\title{
Large-Scale 3D Electromagnetic Field Analysis for Estimation of Stator End Region Loss in Turbine Generators
}

\author{
Kenta Motoyoshi*a) Member, Haruyuki Kometani* Senior Member \\ Nobuyuki Sora* Non-member, Susumu Maeda* Non-member
}

(Manuscript received Dec. 20, 2016, revised April 28, 2017)

\begin{abstract}
Improving the energy efficiency and increasing the power density of indirectly hydrogen-cooled turbine generators used in high efficiency combined-cycle power plants is important due to global warming and increasing power demands. When the output current is increased for achieving high power density, the stray load loss at the stator end region increases due to leakage flux from the armature and field coils. Therefore, it is necessary to evaluate the temperature of the stator end region under the condition of leading power factor load. In this paper, we analyzed the loss density distributions at the end region structures using large-scale 3D electromagnetic field analysis to establish the temperature reliability of an $870 \mathrm{MVA}$ indirectly hydrogen cooled machine, which is the largest class capacity in the world. Thermal analysis was then performed using the loss density distribution obtained from the 3D analysis. The analysis results show good agreement with the measured values.
\end{abstract}

Keywords: turbine generator, eddy current loss, electromagnetic field analysis, stator end region

\section{Introduction}

Improving the energy efficiency and increasing the power density of indirectly hydrogen cooled turbine generators used in high efficiency combined cycle plants is important due to global warming and increasing power demand.

Generally, it is necessary to increase the voltage or the current to increase the output power density. However, the iron loss or the stray load loss also increases with an increase of the voltage or the current.

An example of breakdown of loss generated in an indirectly hydrogen cooled system turbine generator is shown in Fig. 1. As shown in Fig. 1, the stray load loss and iron loss accounts for approximately $15 \sim 20 \%$ and $10 \sim 15 \%$ of the total loss, respectively. Iron loss and stray load loss are defined as the loss excluding both the copper and mechanical losses during iron loss test and copper loss test, respectively. These tests are factory test, where the iron loss test is conducted under no-load condition with the rated terminal voltage at the rated speed, and the copper loss test is conducted under 3phase short circuit condition with the rated armature current at the rated speed.

Generally, the armature current and the terminal voltage are same under both conditions. However, the leakage flux under the condition of the leading power factor load becomes large compared with that under the condition of the lagging power factor load, because of increasing magnetization by the leakage flux of field coils. Therefore, it is necessary to

a) Correspondence to: Kenta Motoyoshi. E-mail: Motoyoshi. Kenta@cj.MistubishiElectric.co.jp

${ }^{*}$ Mitsubishi Electric Corporation

8-1-1, Tsukaguchihonmachi, Amagasakishi, Hyogo 661-8661, Japan

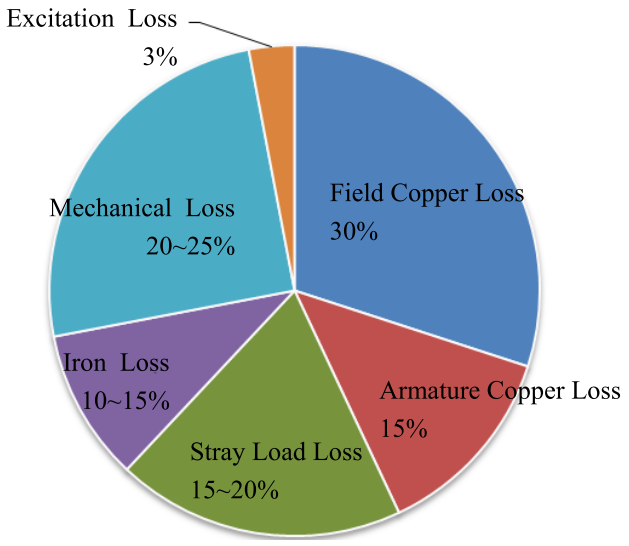

Fig. 1. An example of separation of loss an indirectly hydrogen cooled turbine generator

evaluate the temperature at the end region structures under the condition of the leading power factor load.

However, the load test cannot be performed easily in the factory, and generally only the iron loss test and the copper loss test are performed.

In order to evaluate the temperature of the stator end region structures under the load condition, it is necessary to estimate the loss distribution accurately using 3D electromagnetic field analysis, and until now, several studies for estimation of these losses have been conducted ${ }^{(1)-(4)}$. However, since stator end region structures was not modeled in detail, it is not enough to estimated eddy current loss of stator end region of turbine generators in greater detail in these reference.

In order to estimate these losses accurately, it is necessary to calculate the eddy current loss generated in the structures at the stator end region. However, since the eddy current loss is 
mainly distributed within the skin depth, and the skin depth of magnetic materials is less than $1 \mathrm{~mm}$ and is very small compared with the size of the structures, the number of FEM meshes, becomes over ten of millions. Therefore, in conventional 3D electromagnetic fields analysis, since computational cost is expensive, it was not possible to model in detail and calculate the loss of the structure at the stator end region within a realistic time. Due to this reason, in conventional studies, it was only possible to calculate the eddy current loss with a simplified analysis model of the stator end structures.

Owing to the substantial improvement in performance of computer system, large-scale FEM models can be analyzed ${ }^{(5)}$.

In this paper, we used 15-parallel computing system for large-scale 3D electromagnetic field analysis. Total number of meshes of the FEM model were approximately 7,500,000. In addition, we performed a thermal analysis using the loss distribution from the copper loss test to evaluate the temperature reliability, and the temperature values obtained from the analysis were verified with the measured values.

\section{Analysis Method}

\subsection{Stator End Region Structures of Turbine Genera-}

tors The end region structures modeled in this paper are shown in Fig. 2. The stator end region is composed of the stator cores, the finger plates, the clamp plate, the shield cores, the shield plate and the armature coils. The stator cores are made of laminated magnetic steel sheets, and they are shaped like stairs at the end region as shown in Fig. 2. The finger plates are made of non-magnetic materials, and placed on the both end of the stator cores. The clamp plate is made of solid magnetic material, and clamps the stator cores and the finger plates. The shield cores are made of laminated magnetic steel sheets, and they are shaped also like stairs as shown in Fig. 2. They are set up for reduction of the loss on the clamp plate. The shield cores are clamped by the shield plate which is made of non-magnetic material. Flux is generated in the axial direction since the armature coils are wound along the involute curve.

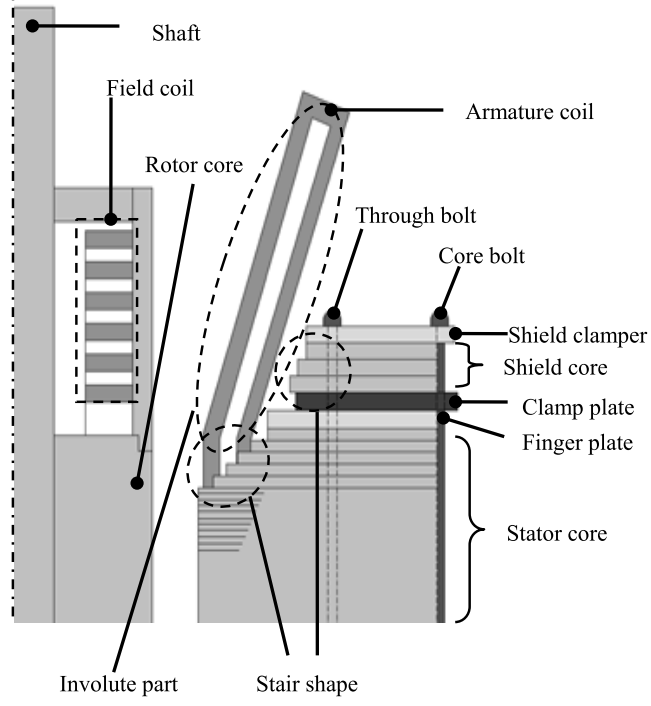

Fig. 2. Schematic view of the stator end region
2.2 Specifications The specifications of the turbine generator are shown in Table 1. In this paper, an 870 MVA indirectly hydrogen cooled turbine generator was analyzed.

2.3 Analysis Models If all of the stator end region structures is modeled without dividing into smaller parts, the number of FEM elements becomes over ten of millions. Therefore, in this paper, the stator end region was divided into 3 parts, since the computational cost of such an ultralarge-scale FEM model is expensive. Figure 3(a) shows the FEM model of loss analysis of the stator core end region and the finger plates. Figure 3(b) shows the FEM model

Table 1. Turbine generator specifications

\begin{tabular}{|c|c|}
\hline NUMBER OF POLE NUMBER & 2 \\
\hline RATED OUTPUT & $870 \mathrm{MVA}$ \\
\hline ROTATION SPEED & $3,600 \mathrm{MIN}-1$ \\
\hline FREQUENCY & $60 \mathrm{~Hz}$ \\
\hline RATED POWER FACTOR & $0.9(\mathrm{LAG})$ \\
\hline LEADING POWER FACTOR & 0.95 \\
\hline
\end{tabular}

Table 2. Detail of stator end region analysis model

\begin{tabular}{|c|c|c|c|c|}
\hline & FEM model & Fig. 3(a) & Fig. 3(b) & Fig. 3(c) \\
\hline \multirow{2}{*}{ Stator } & $\begin{array}{l}\text { Total number of } \\
\text { nodes }\end{array}$ & $7,050,750$ & $2,045,824$ & $2,044,081$ \\
\hline & $\begin{array}{l}\text { Total number of } \\
\text { elements }\end{array}$ & $6,931,008$ & $1,986,768$ & $1,995,840$ \\
\hline \multirow{2}{*}{ Rotor } & $\begin{array}{l}\text { Total number of } \\
\text { nodes }\end{array}$ & 368,135 & 277,184 & 515,070 \\
\hline & $\begin{array}{l}\text { Total number of } \\
\text { elements }\end{array}$ & 362,124 & 271,593 & 496,128 \\
\hline
\end{tabular}

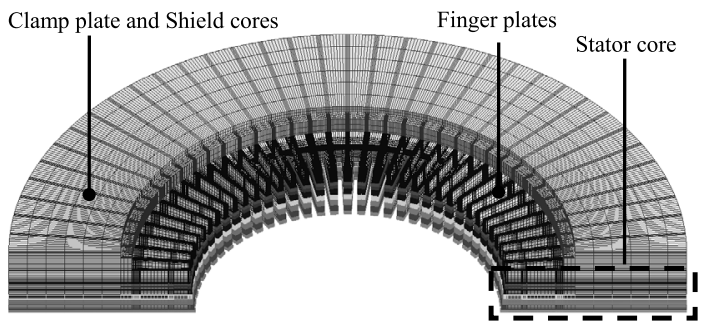

(a) Analysis model of the stator core end region and finger plates

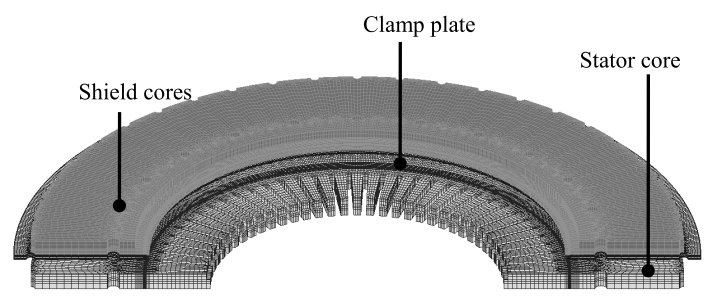

(b) Analysis model of the clamp plate

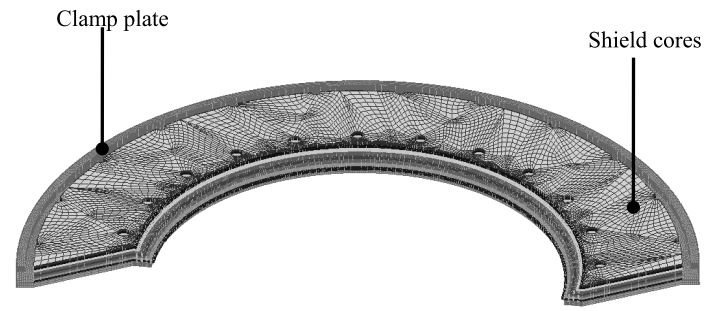

(c) Analysis model of the shield cores and shield clamper

Fig. 3. Eddy current loss analysis model of the stator end region 
Table 3. The performance of the computing system

\begin{tabular}{|c|c|c|}
\hline Computing system & Conventional & Parallel \\
\hline Number of computer & 1 & 5 \\
\hline Number of parallel & 1 & 15 \\
\hline Computation time & $1.7 \mathrm{~h} /$ step & $2.9 \mathrm{~h} / \mathrm{step}$ \\
\hline Total Number of elements & 400,000 & $9,000,000$ \\
\hline
\end{tabular}

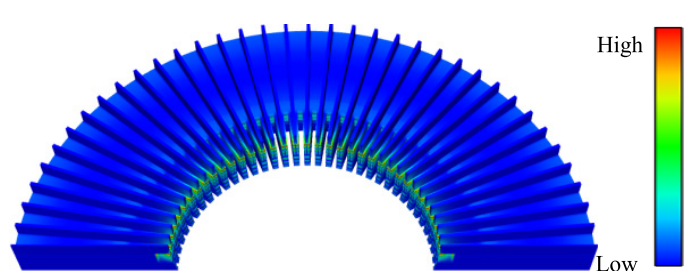

(a) Under condition of the iron loss test

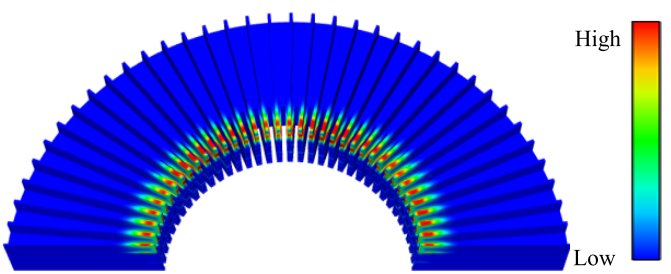

(b) Under condition of the copper loss test

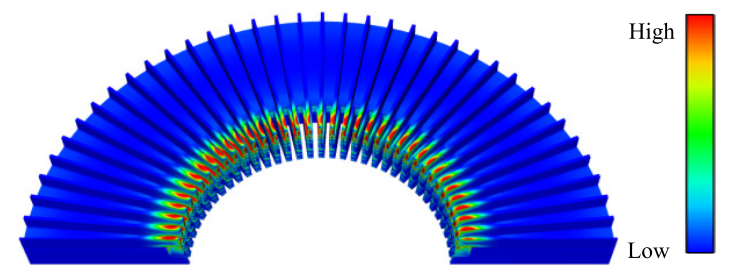

(c) Under condition of the maximum leading power factor

Fig. 4. Eddy current loss density distribution of the stator core and the finger plates

of loss analysis of the clamp plate. Figure 3(c) shows the FEM model of loss analysis the shield cores and the shield plate. In Fig. 3(a) (c), electrical conductivity is applied to the structure parts. For other parts where loss was not calculated, model was simplified and electrical conductivity is not applied. Also, in Fig. 3(a) and (c), since the stator cores and shield cores are made of laminated steel sheets, the characteristic of the conductivity anisotropy was applied ${ }^{(6)}$.

\section{Large-scale 3D Electromagnetic Field Analysis System}

Generally, as the number of elements increases, the calculation time increases by the second power or third power. As shown in Table 3, compared to the conventional analysis model since total number of elements of FEM model has been increased by 22.5 times, an unrealistic time of 1 year would have required to calculate loss analysis of the turbine generators. Therefore, in this paper, in order to calculate the largescale field electromagnetic field analysis, parallel computing system was constructed. With this, the calculation time could be reduced to a realistic 1 month only.

\section{Comparison of the Eddy Current Loss}

The eddy current loss density distributions of the stator cores and the finger plates are shown in Fig. 4. The eddy current loss density distribution of the stator core side and
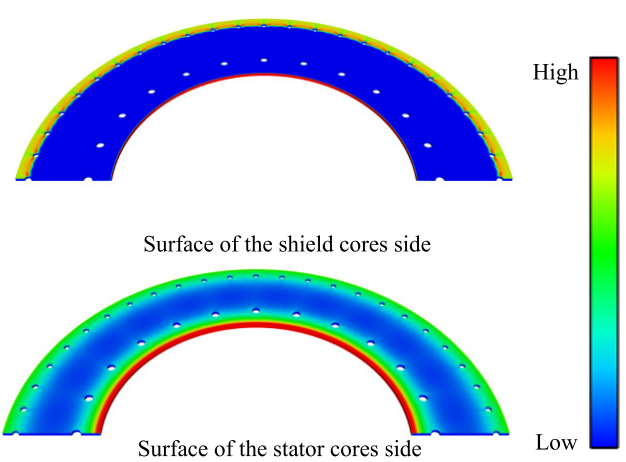

(a) Under condition of the iron loss test
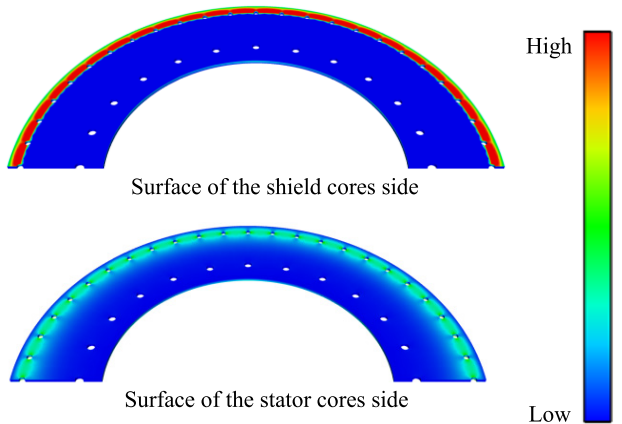

Under condition of the copper loss test

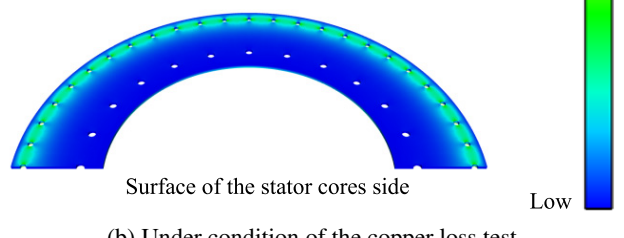

(b) Under condition

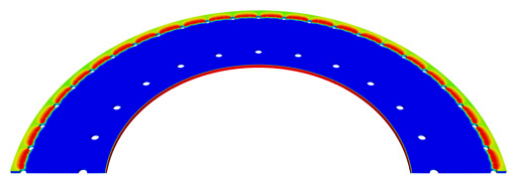

High

Surface of the shield cores side

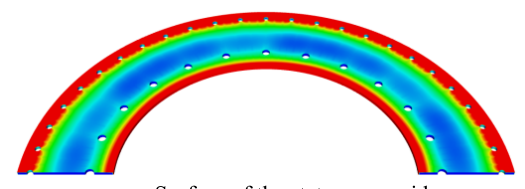

Surface of the stator cores side

(c) Under condition of the maximum leading power factor

Fig. 5. Eddy current loss density distribution of the clamp plate

the shield core side of the clamp plate is shown in Fig. 5. The eddy current loss density distribution of the shield cores is shown in Fig. 6. In each figure of (a) (c), (a) shows the loss density distribution under the condition of the iron loss test, (b) shows loss density distribution under the condition of the copper loss test, and (c) shows loss density distribution under the condition of maximum leading power factor load.

As shown in Fig. 4, under condition of iron loss test and maximum leading power factor load, eddy current loss is concentrated at the inner circumference of the stator core. In contrast, under condition of the copper loss test, eddy current loss is concentrated at the inner circumference of the finger plate.

As shown in Fig. 5, eddy current loss was mainly generated along the inner circumference and surface of the stator core side under condition of the iron loss test and maximum leading power factor load. Under condition of the copper loss test, eddy current loss was only generated along the outer circumference. As shown in Fig. 6, the loss of the shield cores is mainly generated in the inner circumference. The 


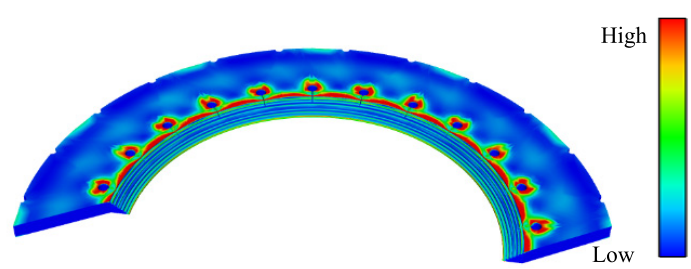

(a) Under condition of the iron loss test

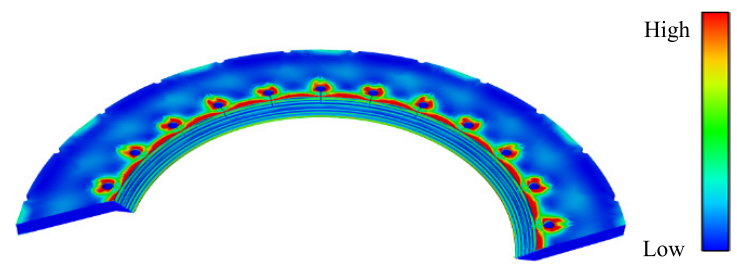

(b) Under condition of the copper loss test

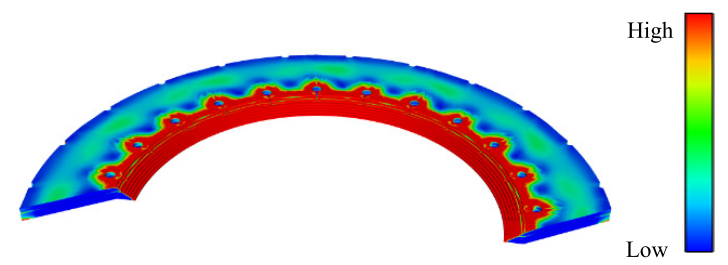

(c) Under condition of the maximum leading power factor

Fig. 6. Eddy current loss density distribution of the shield cores

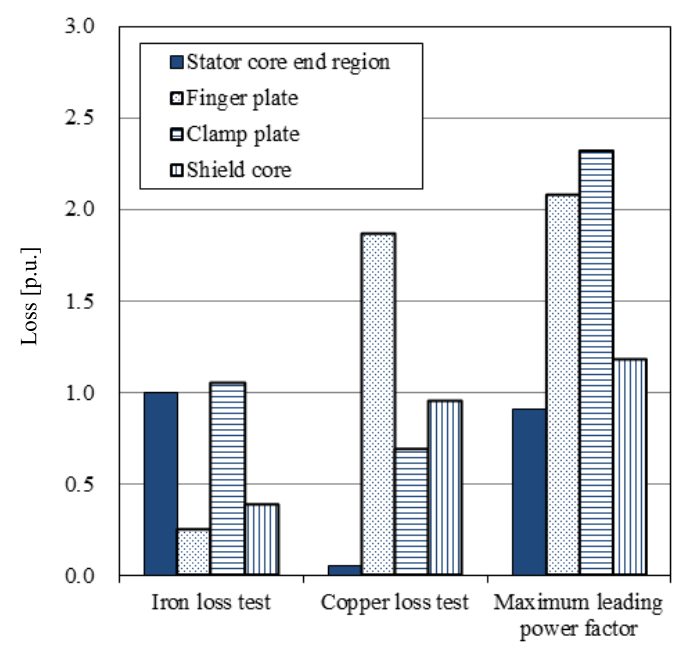

Fig. 7. Eddy current loss at the stator end region

loss density of the end pack is especially compared with the other packs.

The loss values of stator end region structures under each condition are shown in Fig. 7. The hysteresis loss of the magnetic materials is calculated using the iron loss coefficient is included in the analyzed eddy current loss. These values are normalized by the value of the stator core end region under condition of the iron loss test.

Figure 8 shows the distribution of the loss density of the teeth of stator core, which is an enlarged view of Fig. 4(a). As shown in Fig. 8, we find out the eddy current is induced at the stator teeth surface by the axial leakage flux. In Fig. 8, the eddy current loss mentioned is reduced by the slits which are set up at the stator teeth.

As shown in Fig. 7, the loss under the load condition is approximately equal to the loss under the condition of the iron

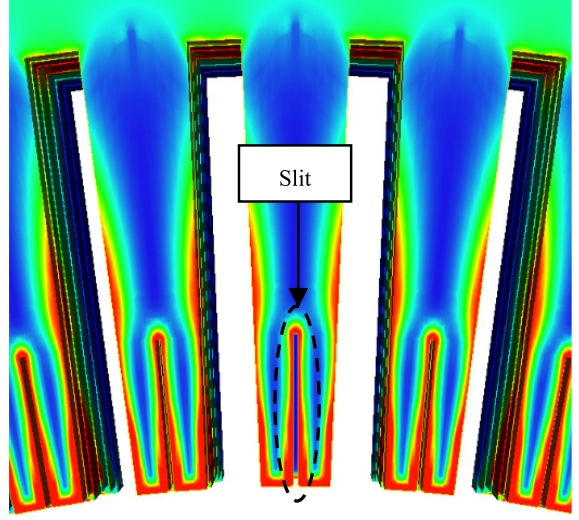

Fig. 8. Eddy current loss distribution at the stator core end region under condition of the iron loss test

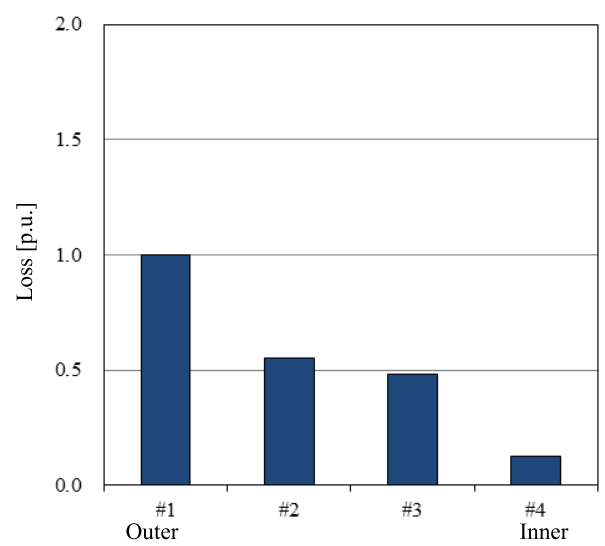

Fig. 9. Detail of eddy current loss in the stator core end packs

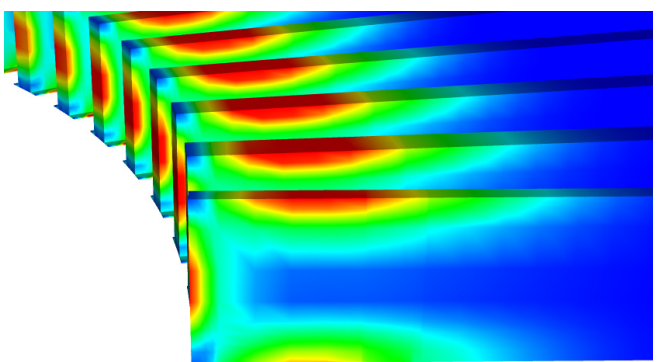

Fig. 10. Eddy current loss density distribution at finger plates under condition of the copper loss test

loss test, which is same terminal voltage with the load condition. Therefore, we can see that the total flux influences the loss value.

In contrast, the loss under the condition of the copper loss test is small, since the flux generated from the field coils and armature coils is almost canceled.

As shown in Fig. 9, the eddy current loss at the end pack of the stator core is large compared with the other inner packs. The loss at each part of stairs shape of stator cores becomes gradually smaller toward inner packs since the axial flux is linked only at the stairs parts directly.

Figure 10 shows the loss density distribution of the finger plates, which is an enlarged view of Fig. 4(b). The eddy current loss of the finger plates under the condition of the copper loss test is mainly generated by the circumferential 
linkage flux at the end of the stator teeth.

As shown in Fig. 10, we can see that the eddy current loss density at the side surface is large, because the circumferential linkage flux from the armature coils is large under the condition of the copper loss test. Therefore, the loss under the condition of the iron loss test without armature current becomes comparatively small compared with under the condition of the copper loss test.

The leakage flux from the outer end region does not reach the clamp plate because of the shield cores. However, the eddy current loss at the inner circumference of the clamp plate is mainly generated by the radial leakage flux from the field coils, since the clamp plate is made of solid magnetic material.

The radial leakage flux is linked not only in the surface of inner circumference but also in the surface of the stator side. Therefore, the eddy current loss is also generated at the surface of the stator cores side at the clamp plate, as shown in Fig. 5.

We can see that the loss at the surface of stator cores side is large compared with the loss at the surface of the shield cores from Fig. 5. The loss under the condition of the iron loss test is small compared with the loss under the load condition as shown in Fig. 7, since the clamp plate is far from the field coils.

The loss under the condition of the copper loss test is comparatively small because the flux of the armature coils is canceled by the flux of the field coils. However, the loss under the condition of maximum leading power factor load is so large because the armature flux is increased by the field flux in the end region.

The loss at the shield cores is mainly generated by axial leakage flux of the armature coils end region because the cores are made of laminated steel sheets. Therefore, the loss under the condition of the iron loss test is comparatively small, and the loss under condition of the copper loss test is large as shown in Fig. 6 and Fig. 7.

The loss under the condition of maximum leading power factor load is larger than the loss under the condition of the copper loss test, since the flux of the field coils also links at the shield cores.

The eddy current loss is reduced by the slits which are set up at the shield cores, as shown in Fig. 11, since the loss is generated in the surface of the shield cores. From Fig. 11, we can see that the eddy current is induced along the slit and the

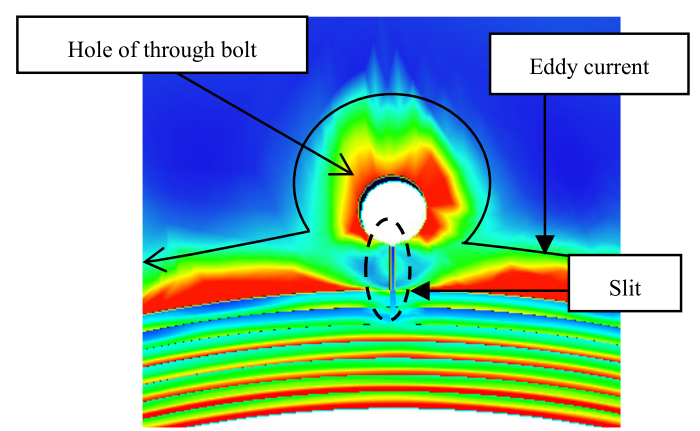

Fig. 11. Eddy current loss density distribution at shield cores surface under condition of the maximum leading power factor hole.

These knowledges described above could not be obtained and visualized without the large-scale 3D electromagnetic field analysis.

\section{Thermal Analysis of Stator end Region}

In this section, the temperature of the stator end region structures is analyzed using the loss density analyzed by 3D electromagnetic field analysis. The temperature distribution under the condition of the copper loss test is shown in Fig. 12. The points of $1 \sim 4$ in Fig. 12 are measurement points. Point 1 indicates the upside of the shield plate. Point 2 indicates the upside of the shield core end. Point 3 indicates the upside of center of the shield core. Point 4 indicates the upside of the finger plates.

As shown in Fig. 12, the temperature of the finger plates is higher than other structures. This is because the loss of the finger plates is larger than other structures, as shown in Fig. 7. The temperatures of each point are shown in Fig. 13, where, the values are normalized by measurement values. As shown in Fig. 13, the temperatures, which are analyzed by the thermal analysis shows a good agreement with the measured values within $5 \%$ errors.

From the above, it seems that the loss distribution and the temperature are estimated accurately. Therefore, we can see that the large-scale 3D electromagnetic field analysis system is effective tool for evaluating the temperature reliability of the turbine generators.

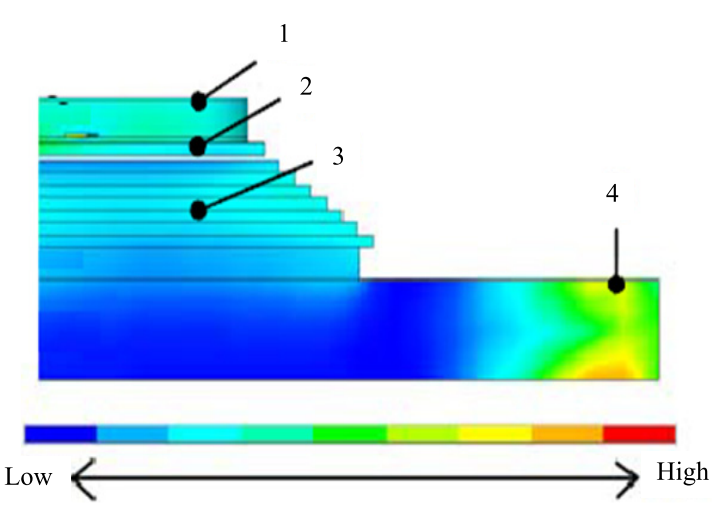

Fig. 12. Temperature distribution of stator end region

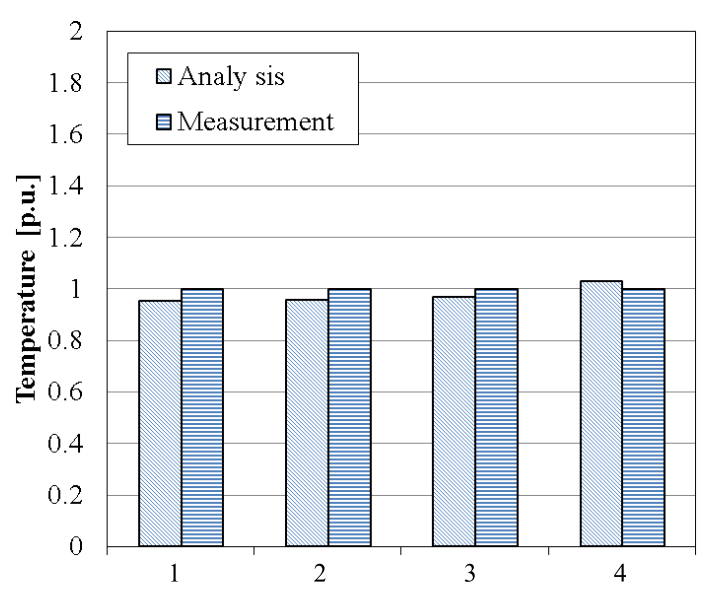

Fig. 13. Comparison of the temperature between the analysis and measurement 


\section{Conclusion}

In the paper, the loss density of the stator end region structures is analyzed by large-scale 3D electromagnetic field analysis using 15-parallel computing system. A thermal analysis is performed using the loss density distribution. The temperatures obtained by the thermal analysis are good agreements with the measured values. The knowledge obtained by these analyses are following;

- The loss of the stator core end region is mainly generated by the axial flux, and the influence of the total flux is large.

- The loss of the finger plates at the side surface is large under the condition of the copper loss test. Therefore, we can conclude that the loss is mainly generated by the circumferential leakage flux from the armature coils.

- The loss of the clamp plate is mainly generated by the radial leakage flux in both the inner circumference and the surface of the stator core side. The leakage flux of the armature coils at the stator end region increases the leakage flux of the field coils under the condition of maximum leading power factor load. Therefore, the loss under the condition of maximum leading power factor load is so large compared with the under condition of the lagging power factor load.

- The loss of the shield cores is mainly generated by the axial leakage flux of the armature coil end region. Therefore, the loss is large under the condition of the copper loss test.

- The temperatures of the stator end region structures analyzed by thermal analysis using these loss densities are good agreements with the measured values within 5\% errors.

- These knowledge could not have been obtained without large-scale 3D electromagnetic field analysis. Large-scale 3D electromagnetic field analysis is effective tool for improving the temperature reliability and energy efficiency in the turbine generators.

\section{References}

( 1 ) H. Kometani, S. Maeda, and K. Suzuki: "Application of Electromagnetic Numerical Analysis for Large Indirectly Hydrogen Cooled Turbine Generators", CIGRE. 2008 A1-109 (2008)

( 2 ) K. Yamazaki, K. Nishioka, A. Nakahara, Y. Furukawa, K. Takahashi, A. Komura, K. Hattori, H. Mikami, and K. Ide: "Basic Study on Loss Reduction Effect by Stator-Teeth Slits in Turbine generators", IEEJ Trans. IA, Vol.131, No.11, pp.1284-1291 (2011) (in Japanese)

( 3 ) K. Yamazaki, S. Tada, H. Mogi, Y. Mishima, C. Kaido, S. Kanao, K. Takahashi, K. Ide, K. Hattori, and A. Nakahara: "Eddy Current Analysis Considering Lamination for Stator Core Ends of Turbine Generators", IEEE Trans on Mag., Vol.44, No.6 (2008)

( 4 ) M. Fujita, T. Ueda, T. Tokumasu, K. Nagakura, M. Kakiuchi, and T. Otaka: "Eddy Current Analysis in the Stator End Structures of Large Capacity Turbine Generators", ICEMS (2009)

( 5 ) T. Nakano, Y. Kawase, T. Ymaguchi, M. Nakamura, N. Nishikawa, and H. Uehara: "Parallel Computing of Magnetic Field for Rotating Machines of the Earth Simulator", IEEE Trans on MAG., Vol.46, No.8 (2010)

( 6 ) H. Kaimori, A. Kameari, and K. Fujiwara: "FEM Computation of Magnetic Field and Iron Loss in Laminated Iron Core using Homogenization Method", IEEE Trans on Mag., Vol.43, No.4, pp.1405-1408 (2007)

Kenta Motoyoshi (Member) received the M.S. degree in electrical en-

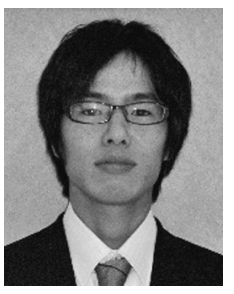
gineering from Kagoshima University, Kagoshima, Japan, in 2010. He joined Advanced Technology R\&D Center of Mitsubishi Electric Corporation in 2010. He has been engaged in research and development of synchronous machine.

Haruyuki Kometani (Senior Member) received the M.S. and Ph.D.

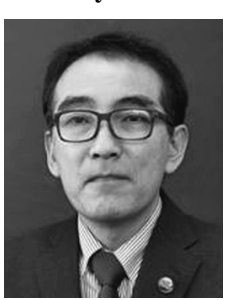
degrees in electrical engineering from Kyoto University in 1989 and 2001, respectively. He joined Advanced Technology R\&D Center of Mitsubishi Electric Corporation in 1989. He has been engaged in research and development of various rotating machines. $\mathrm{He}$ is a senior member of IEEE.

Nobuyuki Sora

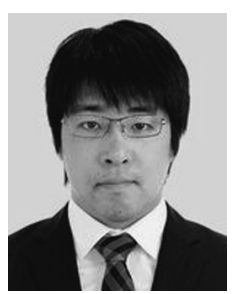

Susumu Maeda

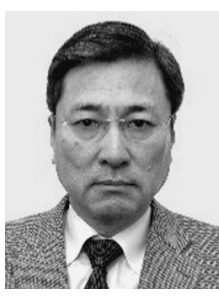

(Non-member) received the M.S. and Ph.D. degrees in electrical engineering from Hokkaido University in 1977 and 2004, respectively. He joined Energy Systems Center of Mitsubishi Electric Corporation in 1977. He has been engaged in development of turbine generators and superconductor generators. 